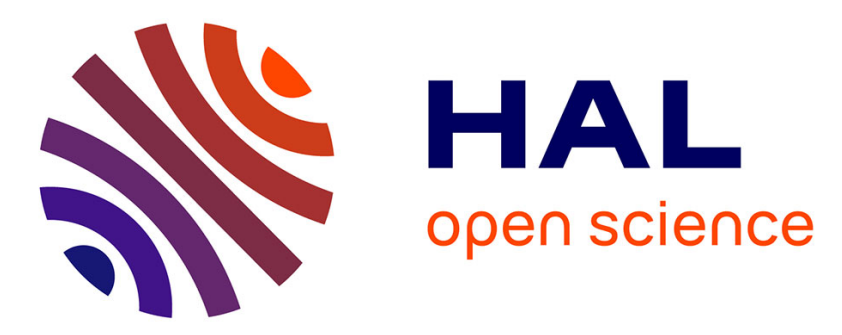

\title{
Evidence of tilted monolayer cybotactic groups in a partially bilayer SA phase
}

\author{
A.M. Levelut, C. Druon
}

\section{To cite this version:}

A.M. Levelut, C. Druon. Evidence of tilted monolayer cybotactic groups in a partially bilayer SA phase. Journal de Physique Lettres, 1982, 43 (6), pp.193-197. 10.1051/jphyslet:01982004306019300 . jpa-00232030

\section{HAL Id: jpa-00232030 https://hal.science/jpa-00232030}

Submitted on 1 Jan 1982

HAL is a multi-disciplinary open access archive for the deposit and dissemination of scientific research documents, whether they are published or not. The documents may come from teaching and research institutions in France or abroad, or from public or private research centers.
L'archive ouverte pluridisciplinaire HAL, est destinée au dépôt et à la diffusion de documents scientifiques de niveau recherche, publiés ou non, émanant des établissements d'enseignement et de recherche français ou étrangers, des laboratoires publics ou privés. 
Classification

Physics Abstracts

$61.30 \mathrm{E}-61.80 \mathrm{C}-77.40$

\title{
Evidence of tilted monolayer cybotactic groups in a partially bilayer $S_{A}$ phase
}

\author{
A. M. Levelut \\ Laboratoire de Physique des Solides (*), Bât. 510, Université de Paris-Sud, 91405 Orsay, France \\ and C. Druon \\ Université de Lille 1, Centre Hyperfréquences et Semiconducteurs $\left(^{* *}\right)$, \\ 59655 Villeneuve d'Ascq Cedex, France
}

(Reçu le 4 décembre 1981, accepté le 26 janvier 1982)

\begin{abstract}
Résumé. - Une étude en diffraction de rayons $\mathrm{X}$ du 4 nonanoate $4^{\prime}$ cyanobiphényle (8 COO CB) montre que la phase $S_{A}$ est de type partiellement bicouche avec une épaisseur de couche valant $1,4 L$ ( $L$ : longueur moléculaire). Elle met aussi en évidence des fluctuations monocouches dans la structure partiellement bicouche. De plus, elle montre que dans la gamme de température correspondant à la phase smectique en surfusion, des groupes cybotactiques monomoléculaires de structure $S_{C}$ apparaissent dans la phase $\mathrm{S}_{\mathrm{A}}$. L'étendue des groupes est de l'ordre de 500 molécules et l'angle d'inclinaison des molécules est de $35^{\circ}$ environ.

Une étude en relaxation diélectrique sur ce composé a été faite. Elle indique que l'énergie d'activation du mouvement de réorientation de la molécule varie de façon inattendue. Lorsque la température décroît, l'énergie diminue à la transition $\mathrm{N}-\mathrm{S}_{\mathrm{A}}$ mais elle augmente pour les températures correspondant à la phase $S_{A}$ en surfusion. Les variations relevées sont en accord avec les renseignements obtenus à partir des expériences de rayons $\mathrm{X}$.
\end{abstract}

\begin{abstract}
A study using X-ray diffraction for 4 nonanoate 4' cyanobiphenyl (8 COO CB) shows that the $\mathrm{S}_{\mathrm{A}}$ phase has a partially bilayer structure with layer thickness $d=1.4 L$ ( $L$ : molecular length). It also shows monolayer fluctuations inside this phase. Moreover, it points out that there exist skewed cybotactic groups of single molecules in the partially bilayer $S_{A}$ phase in the supercooled range of the $S_{A}$ phase. The size of these groups is about 500 molecules, the tilt angle is about $35^{\circ}$.

A study using dielectric relaxation for this compound has also been performed. It shows that the activation energy for reorientational movement of the molecule has unusual behaviour. With decreasing temperature, this energy decreases to the $\mathrm{N}-\mathrm{S}_{\mathrm{A}}$ transition but it increases in smectic supercooled range. Variations obtained are in agreement with information obtained from X-ray experiments.
\end{abstract}

Recently, one of us reported dielectric measurements on the mesomorphic states of the 4 nonanoate $4^{\prime}$ cyanobiphenyl (8 COO CB) [1]. These measurements have been performed for $T>40^{\circ} \mathrm{C}$ and the behaviour of this compound is similar to the behaviour of other cyano derivatives such as the 4 octyloxy $4^{\prime}$ cyanobiphenyl (8 O CB) and 4 octyl 4' cyanobiphenyl (8 CB) [2].

$\left(^{*}\right)$ Laboratoire associé au C.N.R.S.

$\left({ }^{* *}\right)$ LA C.N.R.S. no 287. 
The different phases of $8 \mathrm{COO} \mathrm{CB}$ are :

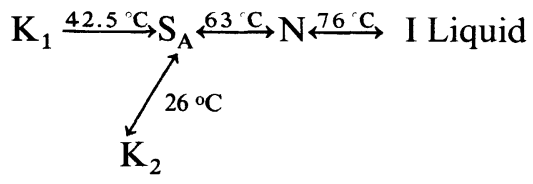

We want to underline here unusual observations made during X-ray and dielectric experiments in the supercooled range of the $\mathrm{S}_{\mathrm{A}}$ phase of this compound.

First, let us recall that SmA phases of cyano derivatives usually have a layer thickness $(d)$ larger than the molecular length $(L)$ [3]. Moreover unexpected sequences of phases could be observed with decreasing temperature :

and

$$
\begin{aligned}
& \mathrm{IL} \leftrightarrow \mathrm{N} \leftrightarrow \mathrm{S}_{\mathrm{A}} \leftrightarrow \mathrm{N} \leftrightarrow\left(\mathrm{S}_{\mathrm{A}}\right) \\
& \mathrm{IL} \leftrightarrow \mathrm{N} \leftrightarrow \mathrm{S}_{\mathrm{A}} \leftrightarrow \mathrm{S}_{\mathrm{C}} \leftrightarrow \mathrm{N} \leftrightarrow\left(\mathrm{S}_{\mathrm{C}}\right)
\end{aligned}
$$

$$
\mathrm{S}_{\mathrm{A}} \leftrightarrow \mathrm{S}_{\mathrm{A}} \text { transitions }
$$

This rich polymorphism can be explained by the coexistence of two kinds of periodic fluctuations [7] : a density wave of one molecular length and a dipolar wave inducing layers of thickness $d$, $1 L \leqslant d \leqslant 2 L$.

The SmA $\leftrightarrow$ SmA transition generally occurs in the case of $d>1.6$ molecular length, while the reentrant nematic is surrounded at high temperature by a partially bilayer smectic $\mathrm{A}$ or $\mathrm{C}$, $d$ or $d / \cos \theta \simeq 1.2-1.4 L$ (where $\theta$ is the tilt angle of a SmC phase) and on the low temperature side by a monolayer smectic phase. The richest polymorphism is observed with three phenyl rings per molecule while two phenyl rings per molecule have only shown the IL $\leftrightarrow N \leftrightarrow \operatorname{SmA} \leftrightarrow N$ sequence. The $8 \mathrm{COO}$ CB does not exhibit a reentrant nematic at atmospheric pressure. Nevertheless the SmA phase is stable down to room temperature when decreasing temperature and the observation made at room temperature gives a new insight on the structure of the smectic A phase.

1. X-ray experiments. - The sample is put in a Lindeman glass capillary tube and aligned by a $0.3 \mathrm{~T}$ magnetic field in the nematic phase. A monochromatic $\mathrm{CuK} \alpha \mathrm{X}$-ray beam reflected by a double bent pyrolitic graphite crystal irradiates the sample; the diffracted X-rays are collected on a flat film; the temperature of the sample is stable within $\pm 0.5^{\circ} \mathrm{C}$.

At high temperature in the SmA phase, the X-ray pattern is typical of an oriented sample and we only observed the first order of reflection on the layers. The layer thickness is $33.1 \pm 0.2 \AA$ while the length of the molecule is about $24 \AA$. When the sample is brought to room temperature $\left(25^{\circ} \mathrm{C}\right.$ ) the X-ray pattern (Fig. 1) shows the same layer thickness, but we observe diffuse intensity scattered out of the Bragg spots :

i) Around the Bragg spots, the scattered intensity is localized in a disc perpendicular to the director. This diffuse scattering comes from the undulation modes of the layer and since the intensity is higher at $25^{\circ} \mathrm{C}$ by at least an order of magnitude than at $55^{\circ} \mathrm{C}$ the frequencies of these modes are decreasing as the sample is cooled down to room temperature.

ii) Another disc is localized perpendicularly to the director at a distance $q_{z}$ from the centre $q_{z}=2 \pi / 23 \AA$. The maximum intensity corresponds to the external boundary of the disc. This pattern is similar to the diffraction pattern of skewed cybotactic groups which can be seen in the nematic phase near the $\mathrm{N} \rightarrow \mathrm{SmC}$ transition [8]. In fact the intersection of one disc with the plane of observation consists of two diffuse spots joined by a diffuse line. From the extension of the diffuse spot, we can estimate the size of the cybotactic groups. 




Fig. 1. - X-ray pattern obtained at $25^{\circ} \mathrm{C}$. The arrow gives the alignment direction.

Since the scattering vector projection along the director corresponds to a periodicity of one molecular length, we can assert that we have monolayer fluctuations inside the partially bilayer SmA phase.

The coexistence of two longitudinal wave-lengths has already been proved in the X-ray patterns of many smectic $A$ and nematic phases of cyano or nitro derivatives. Nevertheless the case of $8 \mathrm{COO} \mathrm{CB}$ appears to be a new one. In the nematic phase and particularly in the reentrant nematic, cybotactic groups of two different layer thicknesses can coexist. Depending of the smectic phases which surround the nematic one, we observed normal or skewed cybotactic groups $[9,10]$. In monolayer $\mathrm{SmA}$ phases $\left(\mathrm{SA}_{1}\right)$, we observed diffuse scatterings localized on rings corresponding to partial bilayer fluctuations [11]. These fluctuations can be coupled to the main monolayer periodicity or not. In the first case, we have a two dimensional array of blocks of monolayer and partial bilayer. In the second case, the localization of the diffuse scattering out of the normal to the layer implies the existence of tilted groups of dimers. Until now we have observed monolayer fluctuation only in SmA with large layer thickness $1.6 L<d<2 L, L$ being the molecular length and $d$ the layer thickness, such fluctuations are always of SmA type.

In the case of $8 \mathrm{COO} \mathrm{CB}$, taking into account the fact that we only observe one order of reflection both for the Bragg reflection and for the diffuse scattering, we can speak of tilted monolayer cybotactic groups of molecules inside a partially bilayer smectic A phase $(\operatorname{SmAd})$. The size of these groups corresponds approximately to eight molecules in all directions, the tilt angle is about $35^{\circ}$. In conclusion, from our X-ray observations, we have evidenced the existence of single molecules in a partially bilayer SmA phase. We can also underline that a segregation occurs between pairs and single molecules.

2. Dielectric experiments. - The measurement of real and complex parts of the complex permittivity $\varepsilon^{*}=\varepsilon^{\prime}-j \varepsilon^{\prime \prime}$ is simultaneously performed between $1 \mathrm{kHz}$ and $1 \mathrm{GHz}$. The cell used in this frequency band is constituted by a plane capacitor located at the end of a coaxial line [12]. The temperature of the sample is stable within $\pm 0.2{ }^{\circ} \mathrm{C}$. The orientation in the nematic phase is achieved by means of an external static magnetic field of $0.3 \mathrm{~T}$. To obtain the alignment in the smectic phase, the sample is cooled slowly in the field from the nematic to the smectic phase.

Figure 2 shows the Cole and Cole diagram obtained for the $S_{A}$ phase at $T=45^{\circ}$ with the electric field parallel to the director. Whatever the temperature, the domain obtained is a half circle shape with centre on the abscissa axis. Therefore, the corresponding mechanism is of a 
Debye type. It is due to the well known reorientational movement of the molecule round an axis perpendicular to its longitudinal axis over the nematic or smectic potential barrier $[12,13]$. The domain obtained is characterized by its amplitude and critical frequency. The importance of the dipolar moment of the molecule $(3.8 \mathrm{D})$ is the cause of the high amplitude of this domain $\left(\varepsilon_{\max }^{\prime \prime}=5\right)$. The existence of the potential barrier explains the low value of the critical frequency $\left(F_{\mathrm{c}}<10 \mathrm{MHz}\right)$.

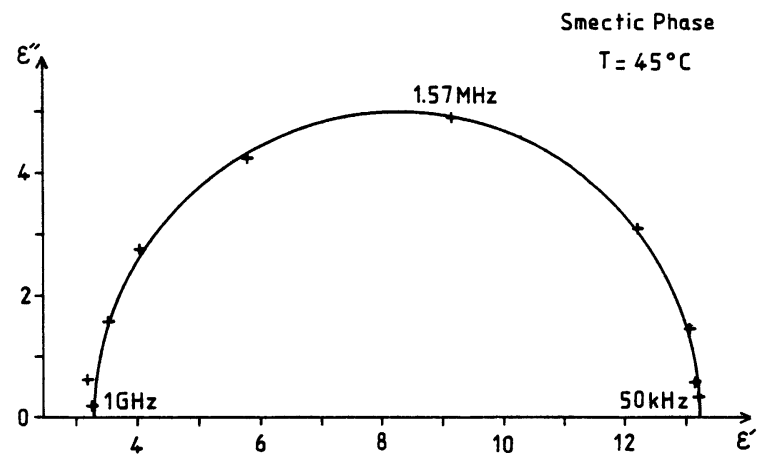

Fig. 2. - Cole and Cole diagram obtained for electric field parallel to director.

Figure 3 shows the evolution of $F_{\mathrm{c}}$ versus the measurement temperature. In this figure, we can observe three parts characterized by straight lines with different slopes. From the latter, we can calculate the activation energy $W$ of the mechanism observed. We obtain :

i) $W=0.76 \mathrm{eV}$ for the nematic phase;

ii) $W=0.50 \mathrm{eV}$ for the smectic phase with $T>30^{\circ} \mathrm{C}$;

iii) $W=0.69 \mathrm{eV}$ for the smectic phase with $T<25^{\circ} \mathrm{C}$.

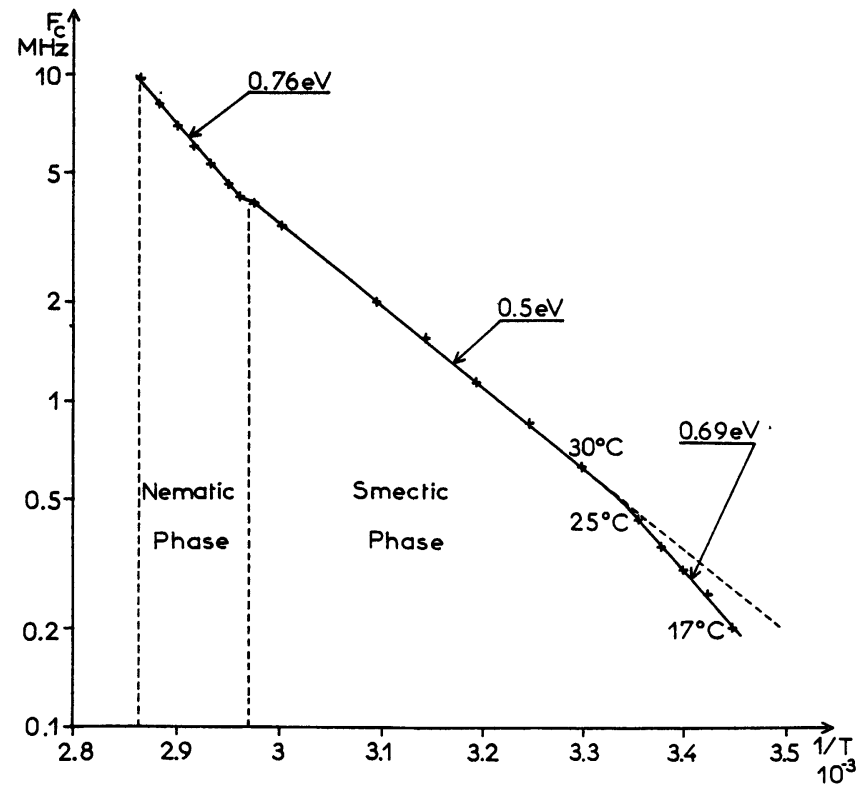

Fig. 3. - Evolution of the critical frequency versus temperature. 
Variations of activation energy at the transition N-S have already been pointed out in a previous article [2], then by other authors [13, 14]. Besides, we note a variation of energy for $T<25^{\circ} \mathrm{C}$. This temperature range corresponds to the supercooled range of the $S_{A}$ phase. The observation of such a variation of energy in a phase is new. It is to be noted that there is no absorption domain in solid phase within this frequency range.

It can be noted that an activation energy lower in the smectic phase than in the nematic phase is obtained with samples whose $\operatorname{SmA}$ phase is partially bilayer $[2,14,15]$. We find again this particularity in the case of $8 \mathrm{COO} \mathrm{CB}$ with $30^{\circ} \mathrm{C}<T<76^{\circ} \mathrm{C}$.

In this temperature range $\mathrm{X}$-ray observations show that the layer thickness is $1.4 \mathrm{~L}$. Therefore, this decrease of energy seems to characterize a molecular association with pair molecules leading to an antiferroelectric order. This association is often observed in the case of molecules with cyano end group [3].

By contrast, if $T<25^{\circ} \mathrm{C}$, the activation energy rapidly increases. The break of slope observed confirms that a variation of structure appears in the sample. This result is consistent with the information obtained by X-ray measurements, that is the appearance of cybotactic groups in the SmA phase.

Note that an increase of activation energy has also been found for another compound [16] when a partially bilayer structure becomes a monolayer one with the sequence :

$$
\mathrm{S} \leftrightarrow \mathrm{N} \longleftrightarrow \mathrm{S} \leftrightarrow \mathrm{N} \longleftrightarrow \mathrm{IL} .
$$

All these results in dielectric relaxation are in agreement with the X-ray observations.

Acknowledgments. - We are indebted to J. C. Dubois and A. Beguin for the synthesis of the compound.

\section{References}

[1] Druon, C. Communication au 6e Colloque Optique Hertzienne et Diélectrique, Toulouse, 14 au 16 septembre 1981.

[2] Druon, C., Wacrenier, J. M., Ann. Phys. 3 (1978) 199.

[3] Gray, G. W., Lydon, J. E., Nature 252 (1974) 221.

Leadbetter, A. J., Frost, J. C., Gaughan, J. P., Gray, G. W., Mosley, A., J. Physique 40 (1979) 375.

[4] Cladis, P. E., Phys. Rev. Lett. 35 (1975) 48.

Hardouin, F., Sigaud, G., Achard, M. F., Gasparoux, H., Phys. Lett. 71A (1979) 347.

[5] Weissflog, W., Pelzl, G., Wiegeleben, A., Demus, D., Mol. Cryst. Liq. Cryst. Lett. 56 (1980) 295.

[6] Sigaud, G., Hardouin, F., Achard, M. F., Gasparoux, H., J. Physique Colloq. 40 (1979) C3-356.

[7] Prost, J., Liquid Crystal of One and Two-Dimensional Order, Springer Series in Chemical Phys. (Springer, Berlin) 1980, p. 125.

[8] De VRies, A., Mol. Cryst. Liq. Cryst. 10 (1970) 219.

[9] Hardouin, F., Levelut, A. M., J. Physique 41 (1980) 41.

[10] Hardouin, F., Levelut, A. M., Nguyen Huu Tin, Sigaud, G., Mol. Cryst. Liq. Cryst. Lett. 56 (1979) 35.

[11] Hardouin, F., Levelut, A. M., Sigaud, G., J. Physique 42 (1981) 71.

[12] Druon, C., WaCrenier, J. M., J. Physique 38 (1977) 47.

[13] Bata, L., Buka, A., Mol. Cryst. Liq. Cryst. 63 (1981) 307.

[14] Ratna, B. R., Shashidhar, R., Rao, K. U., Liquid Crystal, S. Chandrasekhar (Heyden, London) 1980, p. 135.

[15] Druon, C., to be published.

[16] Benguigui, L., Hardouin, F., J. Physique Lett. 42 (1981) L-111. 